Rev. salud pública. 14 (1): 67-80, 2012

\title{
Dimensiones culturales sobre el Dengue en profesionales de la salud de México y Colombia
}

\section{Cultural dimensions concerning healthcare workers in Mexico and Colombia having dengue}

\author{
Teresa M. Torres-López ${ }^{1}$, Rubén Soltero-Avelar² y Juana I. Herrera-Pérez ${ }^{1}$
}

\begin{abstract}
1 Departamento de Salud Pública, Centro Universitario de Ciencias de la Salud. Universidad de Guadalajara. Guadalajara, Jalisco, México. tere.torres.cucs@gmail.com, imeldaherrera2002@hotmail.com

2 Departamento de Psicología Aplicada, Centro Universitario de Ciencias de la Salud Universidad de Guadalajara. Guadalajara, Jalisco, México. rubensoltero@gmail.com
\end{abstract}

Recibido 19 Abril 2011/Enviado para Modificación 11 Febrero 2012/Aceptado 22 Febrero 2012

\section{RESUMEN}

Objetivo Comprender las dimensiones culturales del dengue en profesionales de la salud de México y Colombia. A fin de generar elementos para la formación y actualización de los éstos en la prevención y atención de dicha enfermedad.

Método Estudio antropológico cognitivo. Realizado en las ciudades de Morelia, México y Santiago de Cali, Colombia. Participaron un total de 197 profesionales de salud seleccionados por muestreo propositivo. Se utilizaron las técnicas de listados libres y el sorteo de montones. Se indagaron términos asociados al concepto dengue y grupos de dimensiones conceptuales.

Resultados Las concepciones culturales del dengue en los participantes de México hicieron énfasis en la prevención. Los de Colombia mostraron un lenguaje biomédico y su interés se centró en la sintomatología. En general se mostró una visión integral del dengue que incluye la visión médica y aspectos sociales interrelacionados.

Conclusiones Los profesionales de la salud requieren de mayor formación en torno al tema del dengue y su prevención.

Palabras Clave: Dengue, fiebre hemorrágica, dengue, antropología cultural, factores culturales, enfermedades transmisibles emergentes, investigación cualitativa (fuente: DeCS, BIREME).

\section{ABSTRACT}

Objective Understanding cultural dimensions concerning Mexican and Colombian healthcare workers suffering from dengue to produce information and elements for healthcare and prevention. 
Method This was a cognitive anthropological study. Purposive sampling was used to select 197 healthcare workers in Morelia, Mexico, and Santiago de Cali, Colombia; free associations lists and pile sorting were used. Terms associated with the concept of dengue and conceptual dimension groups were investigated.

Results Participants cultural conceptions regarding dengue in Mexico emphasised prevention, whilst those in Colombia concentrated on biomedical language and symptoms. Overall, a holistic vision was shown which included a medical vision and related social aspects.

Conclusions Health professionals require more information about dengue and its prevention.

Key Word: Dengue, hemorrhagic dengue fever, cultural anthropology, cultural factor, emerging communicable disease, qualitative research (source: MeSH, NLM).

E n la actualidad existen una serie de factores relacionados con el incremento de dengue en Latinoamérica (1). Unos 2,5 mil millones de personas corren el riesgo de contraer la enfermedad. La Organización Mundial para la Salud calcula que cada año puede haber 50 millones de casos de dengue en todo el mundo. En el año 2009 se reportaron 853468 casos de dengue en la región de las Américas, incluyendo 20832 casos de dengue hemorrágico y 326 defunciones, con una tasa de letalidad regional de $1,5 \%$ (2).

La Secretaria de Salud de México en el año 2009, reportó un total de 55 961 casos de dengue (11 396 de dengue hemorrágico) y en el año 2010 se reportaron 28688 casos de dengue (6 336 del tipo hemorrágico) (3).

En Colombia, en el año 2009 se reportaron 49069 casos de dengue (6 695 de dengue grave) (4) y en 2010 se reportaron 43496 casos (3 616 casos de dengue grave). Los departamentos con más casos de dengue durante ese año fueron: Huila, Valle del Cauca, Norte de Santander, Tolima y Santander (5).

Esta situación ha venido a destacar la importancia de contar con más elementos para la planeación, implementación y evaluación de programas preventivos. Por ello se han desarrollado estudios considerando el punto de vista de los actores implicados. La mayoría se han centrado en la población y pocos han tomado en cuenta el punto de vista de los profesionales de la salud. Aún cuando son las personas que participan en la creación de 
programación de prevención, su implementación o bien proporcionan la atención a los enfermos.

El objetivo del estudio fue comprender las dimensiones culturales del dengue en profesionales de la salud de México y Colombia. Con la finalidad de generar elementos para la formación como la actualización académica de los profesionales de la salud en materia de prevención y atención de dicha enfermedad.

\section{MÉTODOS}

Tipo de estudio

Se realizó un estudio de Antropología Cognitiva. La cual estudia la manera en cómo los sujetos de diferentes culturas adquieren información y la procesan para generar decisiones y actuar de acuerdo a los valores normativos de su entorno. La codificación de la información en este enfoque implica un tratamiento estadístico a fin de obtener el análisis de consenso. Es decir, se realiza un análisis cuantitativo de datos cualitativos (ya que implica convertir palabras o imágenes en números) (6).

Contextos

El estudio se realizó en Morelia, México y en Santiago de Cali, Colombia con población de profesionales de la salud de ambos países.

La ciudad de Morelia es la capital del estado de Michoacán en México. Dicho estado contaba para el año 2010 con 4351037 habitantes, Morelia tenía ese mismo año 729279 habitantes (7). El clima es templado de humedad media, con régimen de lluvias en verano de 700 a 1000 milímetros de precipitación anual y lluvias invernales de 5 milímetros anuales promedio (8). En el estado de Michoacán se tuvieron 2561 casos de dengue en 2008; 4350 casos en 2009 (100 del tipo hemorrágico) y 1193 casos en el 2010 (50 del tipo hemorrágico) (9).

La ciudad de Santiago de Cali es la capital del Departamento del Valle de Cauca, Colombia. El cual en el año de 2005 contaba con 4052235 habitantes, mientras que Cali con 2075380 habitantes (10). El Valle del Cauca tiene características climáticas variadas y tiene tres regiones naturales: la región plana entre las dos cordilleras; la región montañosa y la región costera. La ciudad de Santiago de Cali se ubica en la primera región, 
tiene una altitud 995 m.s.n.m. y su temperatura promedio es de $23^{\circ} \mathrm{C}$ (11). El Departamento del Valle del Cauca tuvo 1028 casos de dengue (103 de dengue grave) en junio del año 2010 (12).

Muestra y muestreo

La muestra se participantes se conformó por muestreo propositivo (13). Los criterios de selección fueron: profesionales de la salud, con cinco o más años de ejercicio profesional en alguna institución de salud. En ambos contextos fueron abordados y entrevistados en las instalaciones de su trabajo. Antes de cada entrevista se explicaron los objetivos del estudio y se obtuvo el consentimiento informado verbal, garantizándose a los informantes la confidencialidad y anonimato.

El tamaño de la muestra se basó en el supuesto del modelo de consenso cultural para el estudio de patrones culturales. Romney (14) sugiere un tamaño mínimo de 17 informantes para clasificar el $95 \%$ de las preguntas correctamente, bajo un promedio de competencia cultural esperada de 0,5 $\mathrm{y}$ un nivel de confianza de 0,95 .

El trabajo tuvo dos recolecciones de datos, entre agosto y noviembre de 2009: una con la técnica de listados libres y otra con la técnica de sorteo de montones (pile sorting) (15). Participaron 197 personas (provenientes de los dos contextos) de entre 23 y 65 años de edad. En Morelia se entrevistó a 80 personas en la primer fase ( 47 mujeres y 33 hombres) y a 39 en la segunda (20 mujeres y 19 hombres) con una edad promedio de 41,6 años. 40 personas reportaron haber padecido dengue ( 23 mujeres y 17 hombres). En Santiago de Cali se entrevistó a 40 personas en la primer fase (22 mujeres y 18 hombres) y a 38 en la segunda (20 mujeres y 18 hombres) con un promedio de edad de 33,5 años. Tres de los participantes de Santiago de Cali dijeron haber padecido dengue y una mujer reportó que su madre murió de dengue hemorrágico.

Técnicas de recolección de la información

La técnica de listados libres consiste en pedir a los informantes un listado escrito de términos relacionados con la palabra dengue. De las listas de palabras se tabuló su frecuencia para escoger 20 términos, para generar el instrumento de sorteo de montones. Un segundo análisis implicó la categorización de las definiciones dadas a cada palabra, con análisis de contenido temático (16). 
El sorteo de montones consiste en elaborar tarjetas para cada término y pedir a los informantes que formen grupos de tarjetas que contengan los términos más parecidos. Para luego etiquetar cada montón con una palabra que identifique el conjunto seleccionado.

Análisis de la información

Se aplicó análisis de consenso por factorización de componentes principales, análisis dimensionales por conglomerados jerárquicos $\mathrm{y}$ escalas multidimensionales. Con este último análisis se calculó el valor de stress como medida de bondad de ajuste de la representación de los conglomerados. Sturrock sugiere para una representación de 20 términos un valor de corte de stress menor a 0,2 (17). Los distintos análisis se procesaron con el programa computarizado Anthropac V. 4,98 (18).

Triangulación

Se realizó triangulación por investigadores ya que en el proceso de análisis de la información participaron tres investigadores (autores) en forma separada con la misma información recabada, los que llegaron a los mismos resultados.

Aspectos éticos

El proyecto de investigación que fundamentó el presente estudio fue evaluado y aprobado por el comité de ética e investigación del Departamento de Salud Pública de la Universidad de Guadalajara, número IISO/CI/03/10.

\section{RESULTADOS}

El análisis temático sobre el concepto de dengue de mujeres y hombres de Morelia, México se puede observar en la Tabla 1.

Las dos medidas preventivas más destacadas fueron la limpieza y el uso de químicos. La primera fue mencionada tanto para espacios públicos como en espacios privados como son viviendas y patios (Una mujer dijo: "Se limpia los alrededores y casas para que ya no tengan agua sucia en botes, botellas y en los patios"). La prevención por medio del uso de químicos destacó la fumigación y el uso de abate (Un hombre comentó: "debemos mantener el control de diferentes plagas a través de este medio"). 
Tabla 1. Análisis temático sobre el concepto de dengue de mujeres y hombres de Morelia, México, 2009

\begin{tabular}{|c|c|c|c|}
\hline \multicolumn{2}{|r|}{ Mujeres } & \multicolumn{2}{|r|}{ Hombres } \\
\hline $\begin{array}{c}\text { Categoría } \\
(\%)\end{array}$ & Conceptualización & $\begin{array}{c}\text { Categoría } \\
(\%)\end{array}$ & Conceptualización \\
\hline $\begin{array}{c}\text { Prevención } \\
\text { (28) }\end{array}$ & $\begin{array}{l}\text { Limpieza, químico, } \\
\text { descacharrizar, uso } \\
\text { de protección }\end{array}$ & $\begin{array}{c}\text { Prevención } \\
(22,5)\end{array}$ & $\begin{array}{l}\text { Limpieza, químico, } \\
\text { descacharrizar, uso } \\
\text { de protección }\end{array}$ \\
\hline $\begin{array}{c}\text { Aspectos } \\
\text { sociales } \\
(24,3)\end{array}$ & $\begin{array}{l}\text { Participación } \\
\text { comunitaria, más } \\
\text { recursos, mejora de } \\
\text { servicios }\end{array}$ & $\begin{array}{l}\text { Aspectos } \\
\text { sociales } \\
(18)\end{array}$ & $\begin{array}{l}\text { Participación } \\
\text { comunitaria, } \\
\text { mejora de servicios }\end{array}$ \\
\hline $\begin{array}{l}\text { Vector } \\
(11,5)\end{array}$ & $\begin{array}{l}\text { Mosquito } \\
\text { transmisor }\end{array}$ & $\begin{array}{c}\text { Vector } \\
(1,5)\end{array}$ & $\begin{array}{l}\text { Mosquito } \\
\text { transmisor, se } \\
\text { reproduce en agua, } \\
\text { propio del trópico }\end{array}$ \\
\hline $\begin{array}{c}\text { Síntomas } \\
(9,5)\end{array}$ & $\begin{array}{l}\text { Fiebre, malestar, } \\
\text { dolor, náuseas, } \\
\text { diarrea, prurito }\end{array}$ & $\begin{array}{l}\text { Concepto } \\
\text { (13) }\end{array}$ & $\begin{array}{l}\text { Enfermedad } \\
\text { curable, el tipo } \\
\text { hemorrágico } \\
\text { produce muerte, } \\
\text { quebrantahuesos }\end{array}$ \\
\hline $\begin{array}{c}\text { Concepto } \\
(10,2)\end{array}$ & $\begin{array}{l}\text { Enfermedad viral, } \\
\text { el tipo hemorrágico } \\
\text { produce muerte }\end{array}$ & $\begin{array}{c}\text { Síntomas } \\
(12,4)\end{array}$ & $\begin{array}{l}\text { Fiebre, dolor, } \\
\text { erupción cutánea. } \\
\text { En ocasiones } \\
\text { hemorragias }\end{array}$ \\
\hline $\begin{array}{c}\text { Agua y } \\
\text { reservorios } \\
(7,5)\end{array}$ & $\begin{array}{l}\text { Agua limpia y sucia, } \\
\text { estancada en } \\
\text { cacharros, basura } \\
\text { y llantas }\end{array}$ & $\begin{array}{l}\text { Agua y } \\
\text { reservorios } \\
\text { (9) }\end{array}$ & $\begin{array}{l}\text { Agua limpia y } \\
\text { sucia, de charcas, } \\
\text { cacharros y lluvia. }\end{array}$ \\
\hline $\begin{array}{l}\text { Trabajo } \\
\text { (5) }\end{array}$ & $\begin{array}{l}\text { Realizar campañas } \\
\text { de prevención, } \\
\text { trabajo en equipo, } \\
\text { investigación }\end{array}$ & $\begin{array}{l}\text { Trabajo } \\
\text { (5) }\end{array}$ & $\begin{array}{l}\text { Realizar campañas } \\
\text { de prevención, } \\
\text { trabajo en brigadas }\end{array}$ \\
\hline $\begin{array}{l}\text { Atención } \\
\text { (4) }\end{array}$ & $\begin{array}{l}\text { En Centros de } \\
\text { Salud, más, otros } \\
\text { cuidados }\end{array}$ & $\begin{array}{c}\text { Atención } \\
(2,5)\end{array}$ & $\begin{array}{l}\text { Necesidad de } \\
\text { atención médica }\end{array}$ \\
\hline
\end{tabular}

En los aspectos sociales se resaltó la importancia de la participación comunitaria tanto de las autoridades, del personal de salud y de la población en general (un hombre señaló: "se necesita la participación de autoridades comprometidas, el personal de salud y la población, en la salud de sus comunidades"). Además, fueron considerados el papel de las autoridades en la asignación de más recursos para los programas de prevención y mejora del medio ambiente (una mujer dijo al respecto: "Ya que teniendo para nuestra población suficiencia presupuestal, podremos realizar muchas medidas preventivas").

Las diferencias entre hombres y mujeres, fueron que los hombres mostraron mayor conocimiento del vector. Las mujeres resaltaron la importancia de la 
cooperación y organización comunitaria (una mujer dijo: "si todos colaboramos en el control sanitario, de manera conjunta, tendremos un mejor desarrollo sanitario").

Figura 1. Dimensiones del dengue por conglomerados jerárquicos en el grupo de mujeres, Morelia, México, 2009

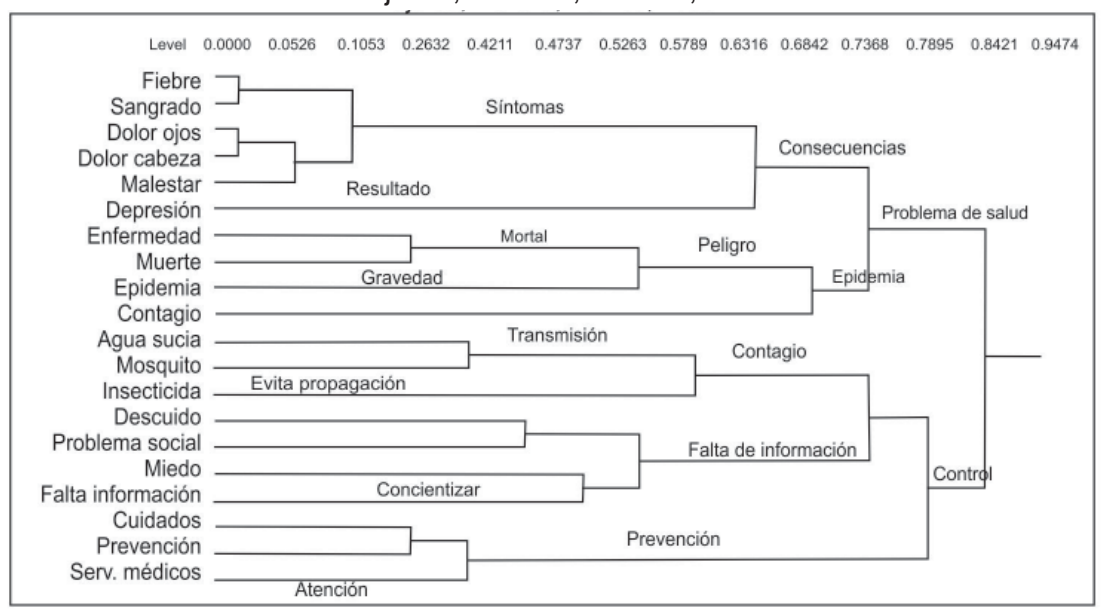

Figura 2. Dimensiones del dengue por conglomerados jerárquicos en el grupo de hombres, Morelia, México, 2009

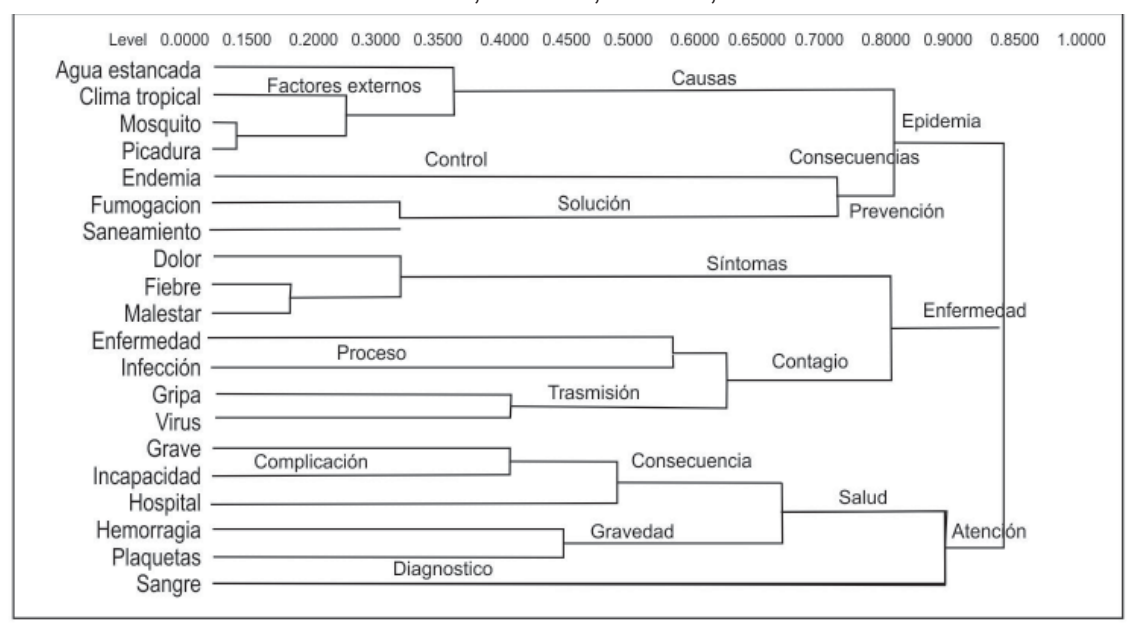

En Morelia las dimensiones descritas en los árboles de conglomerados tuvieron valores de bondad de ajuste adecuados (stress $=0,1$ ) en el análisis de escala multidimensional no métrica. La agrupación que hicieron las mujeres 
de Morelia sobre el término dengue se presenta en la Figura 1. Señalaron dos dimensiones: problemas de salud, incluyó consecuencias (síntomas) y epidemia (Una mujer dijo: "existen lugares de mayor riesgo, en general todos estamos expuestos a ello"). La segunda dimensión fue control, incluyó descuido ("el agua estancada contribuye a la generación del mosco") y prevención ("para poder combatir al dengue es necesaria la fumigación").

Las dimensiones del dengue desde el punto de vista de los hombres se presentan en la Figura 2. Las dimensiones fueron: enfermedad (un hombre indicó: "La llaman quebranta huesos, eso da idea de los síntomas de la enfermedad") y problemas comunitarios. En la dimensión de enfermedad se incluyeron: transmisión, causa y epidemia. En el caso de la dimensión de problemas comunitarios se incluyó impacto social (la cual comprendió: consecuencias y problemas emocionales) y prevención ("hay que prevenir para no tener problemas").

Tabla 2. Análisis temático sobre el concepto de dengue de mujeres y hombres de Cali, Colombia, 2009

\begin{tabular}{|c|c|c|c|}
\hline \multicolumn{2}{|r|}{ Mujeres } & \multicolumn{2}{|r|}{ Hombres } \\
\hline $\begin{array}{c}\text { Categoría } \\
(\%)\end{array}$ & Conceptualización & $\begin{array}{c}\text { Categoría } \\
(\%)\end{array}$ & Conceptualización \\
\hline $\begin{array}{l}\text { Síntomas } \\
\quad(46)\end{array}$ & $\begin{array}{l}\text { Fiebre, dolor, vómito, } \\
\text { malestar, agotamiento, } \\
\text { plaquetas bajas, petequias, } \\
\text { escalofrío y gripe fuerte }\end{array}$ & $\begin{array}{l}\text { Síntomas } \\
\text { (44) }\end{array}$ & $\begin{array}{l}\text { Fiebre, dolor, malestar, } \\
\text { agotamiento, escalofrío, rash, } \\
\text { pérdida de apetito, angustia, } \\
\text { desespero }\end{array}$ \\
\hline $\begin{array}{l}\text { Concepto } \\
\text { (22) }\end{array}$ & $\begin{array}{l}\text { Enfermedad o infección } \\
\text { viral, afecta las defensas, } \\
\text { producida por el piquete del } \\
\text { mosquito }\end{array}$ & $\begin{array}{l}\text { Concepto } \\
(19,1)\end{array}$ & $\begin{array}{l}\text { Enfermedad viral peligrosa, } \\
\text { el tipo hemorrágico puede } \\
\text { producir muerte. Se transmite } \\
\text { por picadura del mosquito }\end{array}$ \\
\hline $\begin{array}{l}\text { Vector } \\
(22)\end{array}$ & $\begin{array}{l}\text { Mosquito transmisor Aedes } \\
\text { hembra, de patas grises. Se } \\
\text { cría en ciertas condiciones } \\
\text { ambientales }\end{array}$ & $\begin{array}{l}\text { Vector } \\
\text { (18) }\end{array}$ & $\begin{array}{l}\text { Mosquito Aedes Aegypty, } \\
\text { necesita control. Habita en los } \\
\text { trópicos y en la jungla }\end{array}$ \\
\hline $\begin{array}{c}\text { Agua } \\
(3,6)\end{array}$ & Agua sucia y estancada & $\begin{array}{l}\text { Aspectos } \\
\text { sociales } \\
\text { (8) }\end{array}$ & $\begin{array}{l}\text { Fracaso de las acciones } \\
\text { del sector salud, fallas en el } \\
\text { saneamiento. }\end{array}$ \\
\hline $\begin{array}{l}\text { Atención } \\
(2,7)\end{array}$ & $\begin{array}{l}\text { Requiere atención } \\
\text { hospitalaria y reposo }\end{array}$ & $\begin{array}{l}\text { Atención } \\
(3,6)\end{array}$ & $\begin{array}{l}\text { Requiere hospitalizar, tomar } \\
\text { líquidos y cuidar plaquetas }\end{array}$ \\
\hline $\begin{array}{l}\text { Prevención } \\
\qquad(1,8)\end{array}$ & Saneamiento y fumigación & $\begin{array}{l}\text { Trabajo } \\
(3,6)\end{array}$ & $\begin{array}{l}\text { Produce incapacidad laboral } \\
\text { y escolar }\end{array}$ \\
\hline \multirow[t]{2}{*}{$\begin{array}{l}\text { Trabajo } \\
(1,8)\end{array}$} & Produce incapacidad laboral & $\begin{array}{l}\text { Prevención } \\
\qquad(2,4)\end{array}$ & Insecticida y vacunas \\
\hline & & Agua $(1,2)$ & Agua estancada \\
\hline
\end{tabular}


El análisis temático sobre el concepto de dengue de mujeres y hombres de Cali, Colombia se presenta en la Tabla 2. La mayoría utiliza un lenguaje biomédico que da cuenta de su formación académica. Llama la atención que mencionaron al agua estancada como reservorio del mosquito (y que no se mencione el agua limpia). Refirieron muchos síntomas, algunas mujeres mencionaron que el dengue se parece a una gripa ("el dengue es como una gripa fuerte y da por temporadas"), los hombres incluyeron estados emocionales (angustia y desesperación). Las medidas preventivas citadas fueron el saneamiento y la fumigación.

Una diferencia entre los géneros fue que sólo los hombres mencionaron aspectos sociales de la enfermedad. Señalaron las fallas de las autoridades en relación al saneamiento ambiental y calificaron de fracaso a las actividades del sector salud ("las medidas sanitarias tomadas por los entes de salud han fracasado"). Resaltaron la importancia de que la población cuente con mayor información sobre el problema.

En Cali las dimensiones descritas en los árboles de conglomerados tuvieron valores de bondad de ajuste adecuados (stress $=0,1$ ) en el análisis de escala multidimensional no métrica. La agrupación que hicieron las mujeres de Cali sobre el término dengue se presenta en la Figura 3. Se presentaron tres dimensiones: La primera es epidemia; la cual se compone de causas (una mujer dijo: "hay condiciones ambientales que influyen en la aparición y en las tendencias epidémicas del dengue") y prevención (incluyó control y solución, una mujer dijo: "el dengue tiene que ver con las condiciones de higiene y vida que hay en el entorno"); la segunda se tituló enfermedad, se compone de síntomas y contagio (incluyó proceso y transmisión, al respecto una mujer dijo: "siempre hay relación con picadura de zancudos de patas grises"); y la tercera atención, comprendió salud (consecuencias, complicación y gravedad) y diagnóstico.

La agrupación que hicieron los hombres de Santiago de Cali sobre el término dengue se presenta en la Figura 4. Las dimensiones fueron: enfermedad y ciclo (incluyó síntomas). La primera se subdividió en riesgos (un hombre indicó: "el trópico es la zona geográfica donde mayor incidencia y probabilidad hay de adquirir la enfermedad"), efectos (un hombre dijo: "se puede producir la muerte si no se trata correctamente, según el tipo de dengue") y salud (la cual comprendió población vulnerable y atención). 
Figura 3. Dimensiones del dengue por conglomerados jerárquicos en el grupo de mujeres, Santiago de Cali, Colombia, 2009

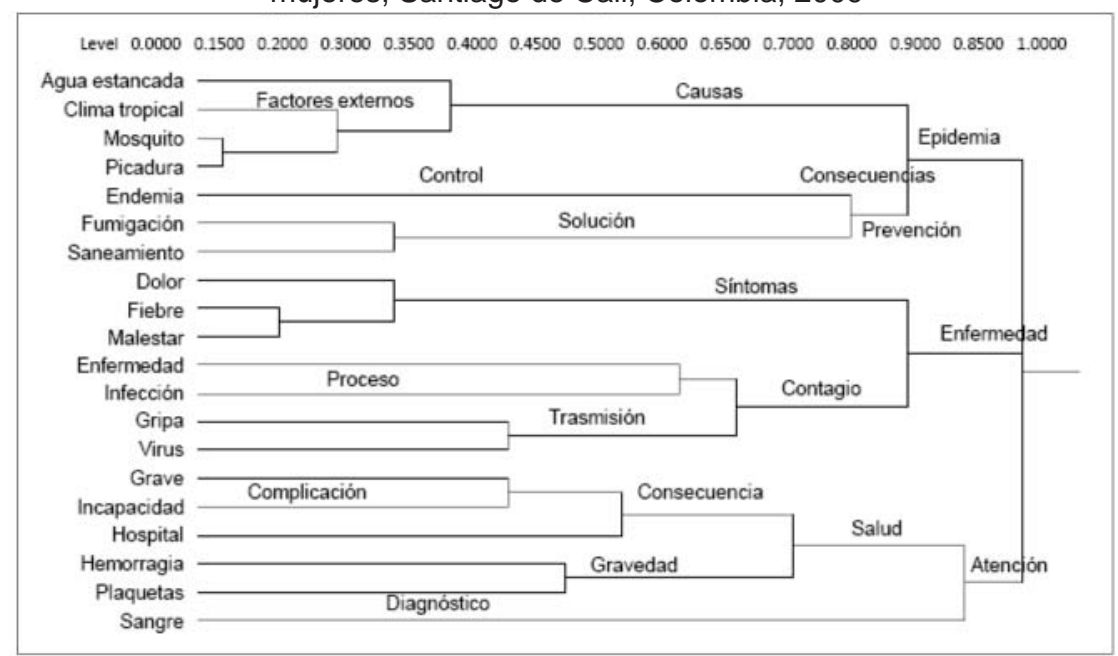

Figura 4. Dimensiones del dengue por conglomerados jerárquicos en el grupo de hombres, Santiago de Cali, Colombia, 2009

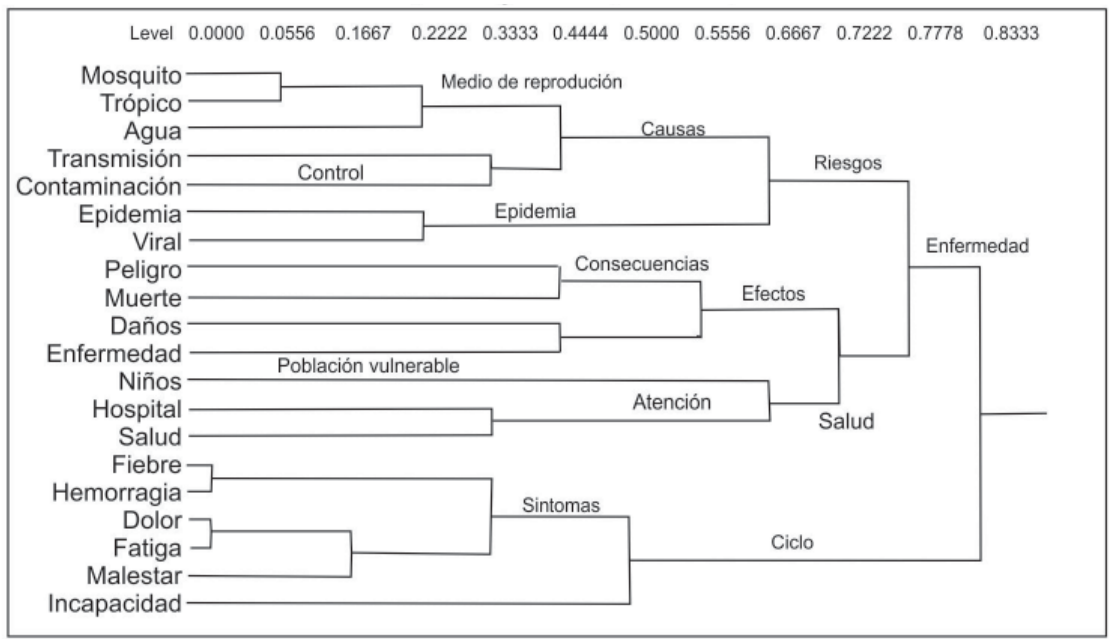


En la Tabla 3 se muestra los valores de consenso cultural obtenidos en cada contexto. En Morelia fue de 7,7 para las mujeres y de 8,6 para los hombres. En Santiago de Cali fue de 9,3 para las mujeres y de 6,7 para los hombres. La regla es que este factor debe calificar más de tres veces la varianza del segundo factor, lo cual sucedió en todos los casos. El porcentaje acumulado de la varianza para la razón entre los factores 1 y 2 fue mayor a $70 \%$ en los dos contextos; la media de la competencia cultural individual fue mayor a 0,50, y los valores mayores a 0,3 en la medida de acuerdo grupal validan el consenso.

Tabla 3. Niveles de consenso cultural sobre el dengue en los contextos estudiados 2009

\begin{tabular}{|c|c|c|c|c|c|c|c|c|}
\hline $\begin{array}{c}\text { Personas } \\
\text { participantes }\end{array}$ & $\begin{array}{c}\text { Razón } \\
\text { del } \\
\text { Factor } \\
1 \text { (F1) }\end{array}$ & $\begin{array}{c}\text { Varianza } \\
\text { Acumulada } \\
\%\end{array}$ & $\begin{array}{l}\text { Razón } \\
\text { del } \\
\text { Factor } \\
2 \text { (F2) }\end{array}$ & $\begin{array}{c}\text { Varianza } \\
\text { Acumulada } \\
\%\end{array}$ & $\begin{array}{l}\text { Razóna } \\
\text { F1:F2 }\end{array}$ & \multicolumn{2}{|c|}{$\begin{array}{l}\text { Competencia } \\
\text { Cultural }^{\mathrm{b}} \\
\text { Media } \mathrm{DE}^{\mathrm{c}}\end{array}$} & $\begin{array}{l}\text { Concor- } \\
\text { dancia } \\
\text { grupal }^{\text {d }}\end{array}$ \\
\hline $\begin{array}{l}\text { Morelia Mujeres } \\
\qquad(n=20)\end{array}$ & 7,7 & 83,6 & 0,8 & 92,3 & 9,5 & 0,6 & 0,2 & 0,4 \\
\hline $\begin{array}{c}\text { Morelia } \\
\text { Hombres }(n=19)\end{array}$ & 8,6 & 81,6 & 1,3 & 94,2 & 6,4 & 0,7 & 0,1 & 0,5 \\
\hline $\begin{array}{c}\text { Cali } \\
\text { Mujeres }(n=20)\end{array}$ & 9,3 & 83,9 & 1,1 & 93,7 & 8,6 & 0,6 & 0,1 & 0,4 \\
\hline $\begin{array}{c}\text { Cali } \\
\text { Hombres }(n=18)\end{array}$ & 6,7 & 78,0 & 1,1 & 91,1 & 5,9 & 0,6 & 0,2 & 0,4 \\
\hline
\end{tabular}

\section{DISCUSIÓN}

En las concepciones culturales del dengue en los participantes de México el énfasis fue en la prevención de la enfermedad. Las diferencias fueron: las mujeres resaltaron la necesidad de contar con mayores recursos para la implementación de programas educativos y saneamiento ambiental.

En Santiago de Cali los participantes mostraron un lenguaje biomédico y su interés se centró en la sintomatología de la enfermedad. Las diferencias fueron: las mujeres destacaron que los síntomas del dengue son similares a los de una gripa fuerte, similar a lo encontrado en otros estudios (19). Mientras que la visión masculina resaltó aspectos sociales relacionados con el dengue: el fracaso de las acciones del sector salud y las fallas en el saneamiento. En otros estudios se ha señalado como responsable de la diseminación de la enfermedad al Sector Salud $(20,21)$. Así la población transfiere la responsabilidad del control del dengue a las autoridades. 
Se presentaron algunas coincidencias en los contextos estudiados. $\mathrm{La}$ primera es que las concepciones culturales sobre el dengue mostraron una visión compleja y holística del problema. Por ello en otros espacios se ha destacado la importancia de implementar programas de prevención que van más allá de la visión médica, aspecto que reconocen los mismos profesionales de la salud (22).

La segunda es que las dos poblaciones de participantes mostraron dimensiones culturales más complejas sobre el dengue, que las que genera la población en general en relación a dicha enfermedad $(23,24)$. Ésta es una visión integral que involucra la mejora en los servicios públicos y la participación conjunta de la población, profesionales de la salud y autoridades en la prevención del dengue.

Otra coincidencia fue que la prevención de la enfermedad está centrada tanto en la limpieza como en el uso de productos químicos para combatir la existencia del mosquito. Esto último sin llegar a considerar los efectos ambientales que se pudieran generar (25).

Por último, si bien se mostró que los participantes tienen información sobre el vector del dengue así como del mecanismo de transmisión. Sin embargo, hay confusión respecto del papel del agua limpia como reservorio y hábitat del mosquito. A igual que en lo presentado en estudios previos donde el agua limpia y su asociación como criaderos es confusa (26). El problema radica en que si no se identifica al agua limpia como un criadero del mosquito, se puede generar un sentimiento de falsa seguridad.

Los profesionales de la salud destacaron la importancia de que la población cuente con la información adecuada que permita llevar a prácticas preventivas. Sólo que ésta no se debe de orientar sólo a la población en general. También los profesionales de la salud requieren de mayor formación en torno al tema del dengue y su prevención: no confundir la sintomatología del dengue con una gripe fuerte, el uso de medidas preventivas no centradas sólo en la fumigación así como el aclarar que el mosquito del dengue se cría en el agua limpia.

Una de las aportaciones teórico metodológicas de estudios como éste es mostrar un acercamiento científico a las concepciones culturales de la población, con estrategias de recolección de información sencilla y más rápida que las entrevistas tradicionales. 
Por otra parte este trabajo muestra las limitaciones propias sobre los estudios del enfoque cognitivo donde se enfatiza los elementos cognoscitivos, mientras que los niveles de análisis grupal, las prácticas y los procesos participativos no son considerados

Agradecimientos: A la Secretaria de Salud del estado de Michoacán (México), a la Universidad Libre Seccional Cali (Colombia) y a los profesionales de la salud que colaboraron en este estudio.

\section{REFRENCIAS}

1. Torres JR, Castro J. The health and economic impact of dengue in Latin America. Cad. Saúde Pública. 2007; 23 Sup 1:S23-S31.

2. Organización Mundial para la Salud. Actualización: programa regional dengue [Internet] (Actualizado al 17 de noviembre de 2009). Disponible en http://new.paho.org/hq/ dmdocuments/2009/Actualizacion_Dengue_Nov17.pdf. Consultado marzo de 2011.

3. Secretaría de Salud. Subsecretaría de Prevención y Promoción de la Salud [Internet]. Panorama epidemiológico de dengue fiebre y fiebre hemorrágica por dengue en entidades federativas, 2010. Disponible en http://www.dgepi.salud.gob.mx/2010/ PDFS/DENGUE/PANORAMAS_2010.zip. Consultado marzo de 2012.

4. Ministerio de Protección Social. Informe Epidemiológico mensual. Semana 1 a 4 [Internet] Informe Epidemiológico Alerta de Dengue en Colombia. Sur América 2010. Disponible en: http://www.minproteccionsocial.gov.co/Documentos\%20 y\%20Publicaciones/INFORME\%20EPIDEMIOLÓGICO\%20\%2001\%202010.pd. Consultado marzo de 2012.

5. Ministerio de Protección Social. Informe Epidemiológico mensual. Semana 5 a 13. Informe Epidemiológico Alerta de Dengue en Colombia. Sur América 2010. Disponible en: http://www.minproteccionsocial.gov.co/Documentos\%20y\%20Publicaciones/ INFORME\% 20EPIDEMIOLÓGICO\%20\%2002\%202010.pdf. Consultado abril de 2011.

6. Bernard HR. Qualitative data, quantitative analysis. Cult Anthropol Methods Journal. 1996; 8(1): 9-11.

7. Instituto Nacional de Estadística y Geografía [Internet]. México en cifras. Información nacional, por entidad federativa y municipios. Disponible en http://www.inegi.org. $\mathrm{mx} / \mathrm{sistemas/mexicocifras/} \mathrm{Consultado} \mathrm{abril} \mathrm{de} 2011$.

8. Instituto Nacional para el Federalismo y el Desarrollo Municipal [Internet]. Enciclopedia de los Municipios y Delegaciones de México. Estado de Michoacán. Disponible en http://www.e-local.gob.mx/wb2/ELOCAL/EMM_michoacan. Acceso abril de 2011.

9. Secretaría de Salud México. Sistema Nacional de Vigilancia Epidemiológica [Internet]. Epidemiología. Sistema único de información. No. 52, Vol. 27. Semana 52, del 26 de diciembre al 1 de enero de 2011. Disponible en http://www.dgepi.salud.gob.mx/ boletin/2010imagen/PDF/BOLETIN/2011/sem2.zip. Acceso marzo de 2012.

10. Departamento Administrativo Nacional de Estadística -DANE [Internet]. Colombia en cifras. Disponible en: http://www.colombiestad.gov.co/index.php?option=com colcifras\&ltemid=58. Acceso abril de 2011.

11. Secretaría de Cultura y Turismo. Datos de Cali y Valle de Cauca [Internet]. Disponible en: http://www.cali.gov.co/publicaciones.php?id=227. Acceso abril de 2011. 
12. Centro Nacional de Enlace|[Internet]. El total casos de dengue notificados por sitio de procedencia hasta el 29 de junio de 2010. Disponible en: http:/l www.minproteccionsocial.gov.co/Documents/Casos $\% 20$ dengue $\% 20 \% 20$ departamentos.pdf. Acceso abril de 2011.

13. Arcury T, Quandt S. Qualitative methods in arthritis research: sampling and data analysis. Arthritis Care Res. 1998;11(1):66-74.

14. Romney A, Batchelder WH, Weller SC. Recent applications of cultural consensus theory. Am Behav Sci. 1987;31(2):163-77.

15. Bernard HR. Structured interviewing II: Cultural Domain Analysis. In: Bernard HR. Research methods in cultural anthropology. Newbury Park: Sage Publications; 2006.

16. Minayo C. El desafío del conocimiento. Investigación cualitativa en salud. Buenos Aires: Lugar Editorial; 1995.

17. Sturrock K, Rocha JA. A multidimensional scaling stress evaluation table. Field Methods. 2000;12(1):49-60.

18. Borgatti S. Anthropac. Lexington: Analytic Technologies; 1996.

19. Claro LBL, Barbosa HC, Garcia ML. Prevenção e controle do dengue: uma revisão de estudos sobre conhecimentos, crenças e práticas da população. Cad. Saúde Pública. Rio de Janeiro. 2004; 20(6):1447-1457.

20. Lefèvrea $F$, Cavalcanti-Lefèvreb AM, Salloum-Scandarc SA, Yassumaro $S$ Representações sociais sobre relações entre vasos de plantas e o vetor da dengue Social representations of the relationships between plant vases and the dengue vector. Rev Saúde Pública. 2004;38(3):405-14.

21. Toledo-Romaní ME, Baly-Gil A, Ceballos-Ursula E, Boelaert M, Van der Stuyft P. Participación comunitaria en la prevención del dengue: un abordaje desde la perspectiva de los diferentes actores sociales. Salud Publica Mex. 2006;48:39-44.

22. Suárez R, González C, Carrasquilla G, Quintero J. An ecosystem perspective in the sociocultural evaluation of dengue in two Colombian town. Cad. Saúde Pública. 2009; 25 (Sup 1):S104-S114.

23.Caballero-Hoyos R, Torres-López TM, Chong-Villarreal F, Pineda-Lucatero A, AltuzarGonzález M, López-Coutiño B. Concepciones culturales sobre el dengue, en tres contextos urbanos de México. Rev. Saúde Pública. 2006;40(1):126-33.

24.Torres-Lopez TM, Caballero-Hoyos R, Barraza-Salas JH, Romero-Paredes JJ. Cultural Conceptions about Dengue in Nayarit, Mexico. Dengue Bulletin. 2006; 30: 223-233.

25. Espinosa-González J [Internet]. Productos Químicos Peligrosos de Uso en Domicilios: Situación de manufactura, empleo, manejo, almacenamiento, transporte, destino final de los desechos y efectos sobre la salud en la ciudad de Panamá. Disponible en: http://www.bvsde.ops-oms.org/bvsare/e/proypan/pan-pqp.pdf. Acceso abril de 2011.

26. Cavalcanti AM, Ribeiro AF, Monteiro GR, Nunes LL, Lefèvre F. Representações sobre dengue, seu vetor e ações de controle por moradores do Município de São Sebastião, Litoral Norte do Estado de São Paulo, Brasil. Cad. Saúde Pública. 2007; 23(7):1696-1706 